\title{
Prevalence, Coincidence and Distribution Patterns of Sesamoid Bones of the Hand
}

\author{
Patrones de Prevalencia, Coincidencia y Distribución de los Huesos Sesamoideos de la Mano
}

\author{
Gurkan Yildiz'; Merve Gursoy²; Tugrul Bulut ${ }^{3}$; Berna Dirim Mete $^{2}$ \& Istemihan Coban ${ }^{4}$
}

YILDIZ, G.; GURSOY, M.; BULUT, T.; METE, B. D. \& COBAN, I. Prevalence, coincidence and distribution patterns of sesamoid bones of the hand. Int. J. Morphol., 39(5):1399-1405, 2021.

SUMMARY: The aim of this study is to identify the prevalence and distribution patterns of sesamoid bones at the metacarpophalangeal (MCP) and interphalangeal (IP) joints and to determine if there is an association between the distribution patterns and age, gender, and hand side. Patients who had a direct radiograph of the hand obtained between 2019-2020 were retrospectively evaluated. All radiographs were evaluated in terms of the prevalence, coincidence, and distribution patterns of sesamoid bones. Presence of an association between distribution patterns and age, sex and side was also assessed. A total of 1501 hand radiographs were included into the study. There were 12 different patterns of sesamoid bone distribution. The most common distribution pattern was the presence of sesamoid bone at the first MCP joint only $(25.8 \%)$. There was a positive correlation between the second and third MCP, second and fifth $\mathrm{MCP}$, second and first IP, third and fourth MCP and fifth MCP and first IP joints. The pattern with a sesamoid bone at the first MCP joint only was more prevalent among males, whereas the pattern involving coincidence of sesamoid bones at the first, second, fifth MCP and first IP joints was more prevalent among females $(\mathrm{p}<0.001, \mathrm{p}=0.031)$. A positive correlation was observed between age and the number of MCP joints with sesamoid bones $(\mathrm{p}<0.001)$. The number of MCP joints with sesamoid bones was found to be higher in females $(\mathrm{p}<0.001)$. This study is important in that it provided anatomical data that can be guiding for clinicians in terms of diagnosis and management of hand disorders.

KEY WORDS: Coincidence; Distribution pattern; Hand; Metacarpophalangeal joint; Sesamoid bones.

\section{INTRODUCTION}

Sesamoid bones are small, oval, or rounded bones embedded in tendons, developing at locations where tendons are in close proximity to the bones and joints. Sesamoid bones are generally found in hands and feet. However, they can also be present in different locations such as the wrist (pisiform bone) or knee (patella). While some sesamoids such as the pisiform bone and patella exist in all individuals, the distribution and prevalence of sesamoid bones of the hand exhibit a wide range of variations. Almost all adults have a sesamoid bone at the first metacarpophalangeal (MCP) joint, whereas the prevalence of sesamoid bones at other MCP and interphalangeal (IP) joints is highly variable (Yammine, 2014; Chen et al., 2015). The reported prevalence for other sesamoid bone locations varies greatly from 3.6$64 \%$ for the second MCP joint to $0-76.5 \%$ for the fifth MCP joint and 5-100 \% for the first IP joint (Bizarro, 1921;
Msamati \& Igbigbi, 2001; Dharap et al., 2007; Amar et al., 2011).The third and fourth MCP joints were reported to have the lowest incidence of sesamoid bones (Kose et al., 2012; Ting et al., 2017; Koo et al., 2017; Civan et al., 2020). The fact that the reported prevalence values vary greatly between different studies is thought to stem from the differences in ethnic origin and genetic variations (Yammine).

Sesamoid bones, which are considered normal anatomic variants, are generally asymptomatic and they are usually encountered as incidental radiographic findings. They rarely become symptomatic due to fractures or degenerative processes. However, sesamoid bone pathologies are usually overlooked since physicians focus more on larger bones. Another issue in routine practice is that sesamoid bones which are rather rare can misdiagnosed

\footnotetext{
${ }^{1}$ Tire State Hospital, Department of Orthopaedics and Traumatology, Izmir, Turkey.

${ }^{2}$ Izmir Democracy University, Faculty of Medicine, Department of Radiology,Izmir, Turkey.

${ }^{3}$ Izmir Kâtip Celebi University, Faculty of Medicine, Ataturk Training and Research Hospital, Department of Orthopaedics and Traumatology, Izmir, Turkey.

${ }^{4}$ Izmir Democracy University, Faculty of Medicine, Department of Anatomy,Izmir, Turkey.
} 
as avulsion fractures in trauma cases, since such bones are not commonly known by all clinicians. This may lead to overtreatment or the use of cross-sectional imaging methods such as computed tomography (CT), resulting in higher radiation exposure. Therefore, it is of utmost importance to know the localization, prevalence and distribution of sesamoid bones. The literature contains various studies on the prevalence of sesamoid bones of the hand. However, details regarding the coincidence of specific distributions of sesamoid bones of the hand, particularly the association between the distribution patterns and age, sex and hand side, have not been sufficiently examined. The aim of this study is to identify the prevalence and the distribution patterns of sesamoid bones at the MCP and IP joints and to determine if there is an association between the distribution patterns and age, sex and hand side.

\section{MATERIAL AND METHOD}

This retrospective study was approved by the Institutional Review Board of Izmir Kâtip Celebi University (IRB\#1007). Since the study was retrospective, informed consent of the patients and providers was not required.

Patient Inclusion and Radiologic Evaluation. Patients who had a direct radiograph of the hand obtained between January 2019 and January 2020 were retrospectively evaluated. Patients who had history of hand surgery, congenital hand anomalies, those who had radiographs of insufficient diagnostic quality and patients under 18 years old were excluded from the study. Hand radiographs of 1501 patients (695 females, 806 males, mean age 42.01) who did not meet the exclusion criteria were included in the study. All patients had posteroanterior (PA) and oblique direct hand radiographs. Radiographs were obtained digitally using Picture archiving communication system (PACS) and radiographic evaluation was performed with the PACS software.

All radiographs were evaluated by a radiologist and an orthopedist in terms of sesamoid bone presence. Any discrepancy was subsequently resolved by consensus. The prevalence and coincidence of the identified sesamoid bones were determined. The data on patient age, sex and hand side were noted from hospital records. Presence of an association between distribution patterns and age, sex and hand side was assessed.

Statistical Analysis. Data was analyzed with the SPSS software version 24.0 (IBM, Armonk, NY). Chi-square test was used to determine if there was a significant difference in terms of sesamoid bone distribution patterns between sexes and hand sides. Spearman's correlation coefficient was used to evaluate the coincidence of sesamoid bones at the MCP joints. The correlation between age and the number of joints with sesamoid bones was also evaluated with the Spearman correlation analysis. $\mathrm{p} \leq 0.05$ was considered statistically significant.

\section{RESULTS}

Of the 1501 patients included in the study, 695 (46.3 $\%$ ) were female and $806(53.7 \%)$ were male. The mean age was 42.01 years (range $=18-96$ years). Among 1501 hand radiographs, $751(50.1 \%)$ belonged to the right side and $750(49.9 \%)$ to the left side.

All patients had a sesamoid bone at the first MCP joint (100\%). The second highest prevalence, i.e. $58.3 \%$ (876/ 1501), of sesamoid bones was observed at the fifth MCP joint. Sesamoid bones were detected at the second MCP joint in 40 $\%$ of the patients $(601 / 1501)$ and at the first IP joint in $32.5 \%$ of the patients (488/1501). The rarest sesamoid bone locations were the third MCP joint with $0.5 \%$ (8/1501) prevalence and the fourth MCP joint with $0.1 \%(2 / 1501)$ prevalence.

There were 12 different patterns of sesamoid bone distribution (Table I). There was a sesamoid bone at one of the MCP joints in $25.9 \%$ of the patients, at two joints in $30.6 \%$, three joints in $29.7 \%$, four joints in $13.6 \%$ and five joints in $0.2 \%$ of the patients. The most common distribution pattern was the one that involved the presence of a sesamoid bone at the first MCP joint only (388/1501 radiographs, 25.8 $\%$ ) (Fig. 1), followed by the patterns involving the coincidence of sesamoid bones at the first and fifth MCP joints (273/1501 radiographs, $18.2 \%$ ) (Fig. 2) and at the first, second and fifth MCP joints (261/1501 radiographs, $17.3 \%$ ) (Fig. 3), respectively. The least common patterns involved the presence of sesamoid bones at all MCP joints except the third (1/1501 radiographs, $0.1 \%$ ) (Fig. 4) and fifth MCP (1/1501 radiographs, $0.1 \%)$ joint and the pattern with sesamoid bones at the first, second, third and fifth MCP and the first IP joint (3/1501 radiographs, $0.2 \%$ ) was also among the least common patterns (Fig. 5). Spearman's correlation coefficient was used to evaluate the coincidence of sesamoid bones at the MCP joints (Table II). Since sesamoid bones are consistently present at the first MCP joint, there was no correlation between the first and any other MCP joints of the hand with respect to the presence of sesamoid bones. Concerning the coincidence of sesamoid bones, there was a positive correlation between the second and third MCP joints ( $\mathrm{r}=0.095$; $\mathrm{p}<0.001)$, the second and fifth MCP joints ( $r=0.319 ; \mathrm{p}<0.001)$, the second and first IP joints $(r=0.158 ; p<0.001)$, the third and fourth MCP joints 
Table I. Distribution patterns of sesamoid bones at the MCP and IP joints.

\begin{tabular}{|c|c|c|c|c|c|c|c|c|c|c|}
\hline \multicolumn{6}{|c|}{ MCP and IP joints } & \multicolumn{2}{|c|}{ Hand side } & \multicolumn{2}{|c|}{ Sex } & \multirow[t]{2}{*}{ Total } \\
\hline MCP 1 & MCP 2 & MCP 3 & $\mathrm{MCP} 4$ & MCP 5 & IP 1 & Right & Left & Male & Female & \\
\hline+ & & & & & & 206 & 182 & 237 & 151 & $388(25.8 \%)$ \\
\hline+ & & & & + & & 131 & 142 & 139 & 134 & $273(18.2 \%)$ \\
\hline+ & + & & & + & & 121 & 140 & 132 & 129 & $261(17.3 \%)$ \\
\hline+ & + & & & + & + & 95 & 103 & 87 & 111 & $198(13.2 \%)$ \\
\hline+ & & & & + & + & 69 & 68 & 60 & 77 & $137(9.1 \%)$ \\
\hline+ & & & & & + & 52 & 50 & 46 & 56 & $102(6.8 \%)$ \\
\hline+ & + & & & & & 50 & 34 & 42 & 42 & $84(5.6 \%)$ \\
\hline+ & + & & & & + & 22 & 27 & 21 & 28 & $49(3.3 \%)$ \\
\hline+ & + & + & & + & & 2 & 2 & 1 & 3 & $4(0.3 \%)$ \\
\hline+ & + & + & & + & + & 2 & 1 & 1 & 2 & $3(0.2 \%)$ \\
\hline+ & + & & + & + & & - & 1 & 1 & - & $1(0.1 \%)$ \\
\hline+ & + & + & + & & & 1 & - & - & 1 & $1(0.1 \%)$ \\
\hline
\end{tabular}

MCP: Metacarpophalangeal, IP: Interphalangeal.

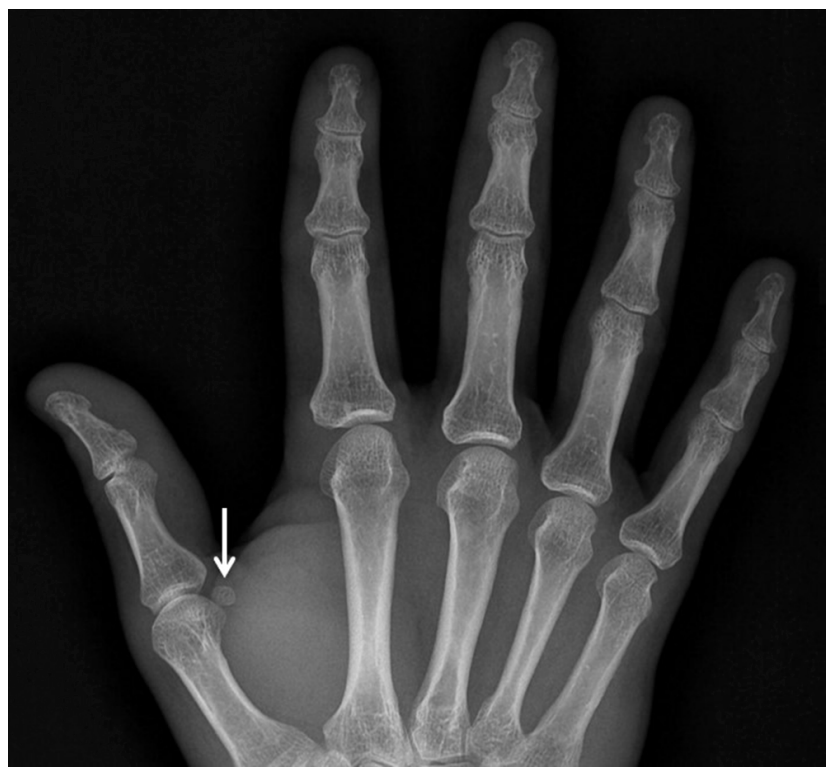

Fig. 1. Posteroanterior radiograph shows sesamoid bone (arrow) only at the first metacarpophalangeal joint which is the most common distribution of sesamoid bones of the hand.

$(\mathrm{r}=0.234 ; \mathrm{p}<0.001)$ and between the fifth MCP and first IP joints $(\mathrm{r}=0.151 ; \mathrm{p}<0.001)$.

Considering the differences between sexes and hand sides in terms of the prevalence of twelve different distribution patterns, it was found that the pattern with a sesamoid bone at the first MCP joint only was significantly more prevalent among males, whereas the pattern involving coincidence of sesamoid bones at the first, second, fifth MCP and first IP joints was significantly more prevalent among females $(p<0.001, p=0.031$, respectively) (Table III). There was no significant difference between the hand sides in terms of distribution patterns $(\mathrm{p}>0.05)$ (Table III).

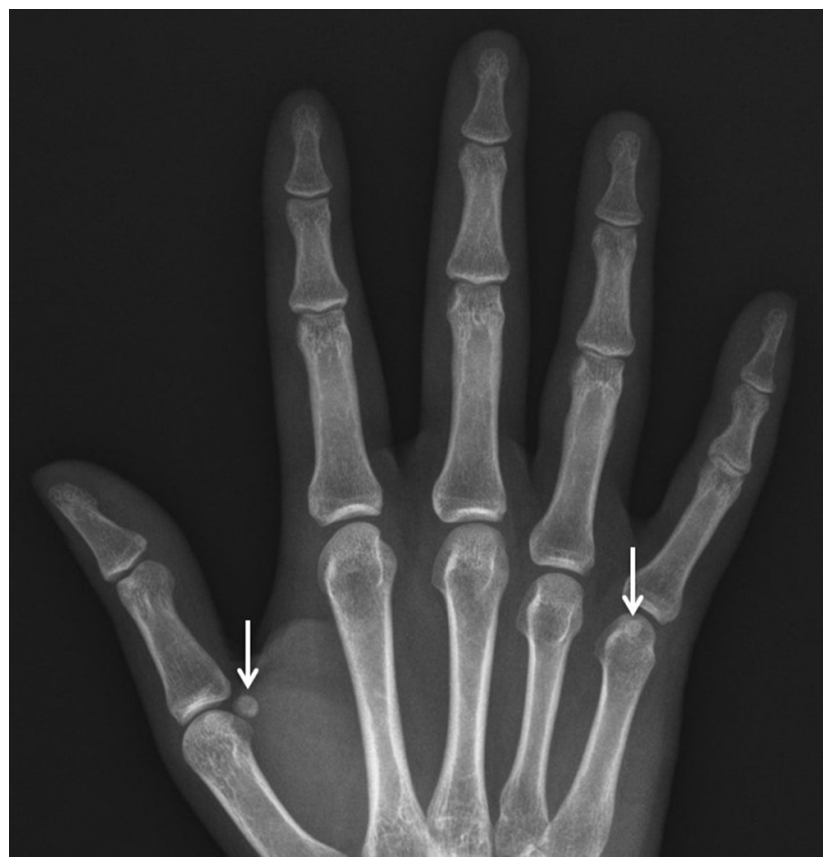

Fig. 2. Posteroanterior radiograph shows sesamoid bones (arrows) at the first and fifth metacarpophalangeal joints which is the second most common distribution of sesamoid bones of the hand.

Considering the relationship between the number of MCP joints with sesamoid bones and age, sex and side, a positive correlation was observed between age and the number of MCP joints with sesamoid bones, which meant that the number of joints with sesamoid bones exhibited an increase in parallel to increasing age $(\mathrm{r}=0.102 ; \mathrm{p}<0.001)$. The number of MCP joints with sesamoid bones was found to be higher in females $(\mathrm{p}<0.001)$. There was no statistically significant relationship between the number of MCP joints with sesamoid bones and side $(\mathrm{p}=0.090)$ (Table IV). 
Table II. Coincidence of sesamoid bones at MCP and IP joints. MCP: Metacarpophalangeal, IP: Interphalangeal, r: Spearman's correlation coefficient, a: no correlation.

\begin{tabular}{|c|c|c|c|c|c|}
\hline Joints & Second & Third & Fourth & Fifth & First IP \\
\hline \multicolumn{6}{|c|}{ First MCP } \\
\hline $\mathrm{r}$ & $\mathrm{a}$ & $\mathrm{a}$ & $\mathrm{a}$ & $\mathrm{a}$ & $\mathrm{a}$ \\
\hline $\mathrm{p}$ & - & - & - & - & - \\
\hline \multicolumn{6}{|c|}{ Second MCP } \\
\hline $\mathrm{r}$ & & 0.095 & $\mathrm{a}$ & 0.319 & 0.158 \\
\hline $\mathrm{p}$ & & $<0.001$ & - & $<0.001$ & $<0.001$ \\
\hline \multicolumn{6}{|c|}{ Third MCP } \\
\hline $\mathrm{r}$ & & & 0.234 & $\mathrm{a}$ & $\mathrm{a}$ \\
\hline $\mathrm{p}$ & & & $<0.001$ & - & - \\
\hline \multicolumn{6}{|c|}{ Fourth MCP } \\
\hline $\mathrm{r}$ & & & & $\mathrm{a}$ & $\mathrm{a}$ \\
\hline $\mathrm{p}$ & & & & - & - \\
\hline \multicolumn{6}{|c|}{ Fifth MCP } \\
\hline $\mathrm{r}$ & & & & & 0.151 \\
\hline $\mathrm{p}$ & & & & & $<0.001$ \\
\hline
\end{tabular}

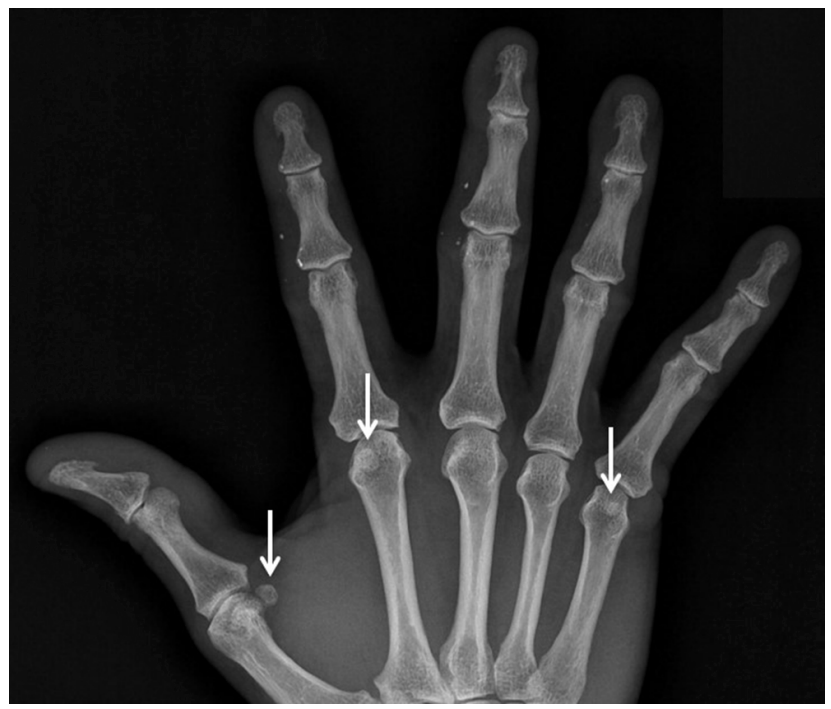

Fig. 3. Posteroanterior radiograph shows sesamoid bones (arrows) at the first, second and fifth metacarpophalangeal joints.

Table III. Comparison of distribution patterns in terms of sex. MCP: Metacarpophalangeal, IP: Interphalangeal.

\begin{tabular}{|c|c|c|c|c|c|c|}
\hline \multirow[t]{2}{*}{ Distribution patterns } & \multicolumn{2}{|c|}{ Sex } & \multicolumn{4}{|c|}{ Hand side } \\
\hline & Female & Male & $\mathrm{p}$ & Right & Left & $\mathrm{p}$ \\
\hline \multicolumn{7}{|l|}{ MCP1 } \\
\hline Negative & $583(79.4 \%)$ & $530(69.1 \%)$ & $<0.001$ & $545(72.6 \%)$ & $568(75.7 \%)$ & 0.162 \\
\hline Positive & $151(20.6 \%)$ & $237(30.9 \%)$ & & $206(27.4 \%)$ & $182(24.3 \%)$ & \\
\hline \multicolumn{7}{|l|}{$\mathrm{MCP} 1+2$} \\
\hline Negative & $692(94.3 \%)$ & $725(94.5 \%)$ & 0.836 & $701(93.3 \%)$ & $716(95.5 \%)$ & 0.073 \\
\hline Positive & $42(5.7 \%)$ & $42(5.5 \%)$ & & $50(6.7 \%)$ & $34(4.5 \%)$ & \\
\hline \multicolumn{7}{|l|}{$\mathrm{MCP} 1+5$} \\
\hline Negative & $600(81.7 \%)$ & $628(81.9 \%)$ & 0.947 & $620(82.6 \%)$ & $608(81.1 \%)$ & 0.454 \\
\hline Positive & $134(18.3 \%)$ & $139(18.1 \%)$ & & $131(17.4 \%)$ & $142(18.9 \%)$ & \\
\hline \multicolumn{7}{|l|}{$\mathrm{MCP} 1+\mathrm{IP} 1$} \\
\hline Negative & $678(92.4 \%)$ & $721(94 \%)$ & 0.209 & $699(93.1 \%)$ & $700(93.3 \%)$ & 0.843 \\
\hline Positive & $56(7.6 \%)$ & $46(6 \%)$ & & $52(6.9 \%)$ & $50(6.7 \%)$ & \\
\hline \multicolumn{7}{|l|}{$\mathrm{MCP} 1+2+5$} \\
\hline Negative & $605(82.4 \%)$ & $635(82.8 \%)$ & 0.852 & $630(83.9 \%)$ & $610(81.3 \%)$ & 0.192 \\
\hline Positive & $129(17.6 \%)$ & $132(17.2 \%)$ & & $121(16.1 \%)$ & $140(18.7 \%)$ & \\
\hline \multicolumn{7}{|l|}{$\mathrm{MCP} 1+2+\mathrm{IP} 1$} \\
\hline Negative & $706(96.2 \%)$ & $746(97.3 \%)$ & 0.241 & $729(97.1 \%)$ & $723(96.4 \%)$ & 0.465 \\
\hline Positive & $28(3.8 \%)$ & $21(2.7 \%)$ & & $22(2.9 \%)$ & $27(3.6 \%)$ & \\
\hline \multicolumn{7}{|l|}{$\mathrm{MCP} 1+5+\mathrm{IP} 1$} \\
\hline Negative & $658(89.6 \%)$ & $707(92.2 \%)$ & 0.088 & $682(90.8 \%)$ & $683(91.1 \%)$ & 0.864 \\
\hline Positive & $76(10.4 \%)$ & $60(7.8 \%)$ & & $69(9.2 \%)$ & $67(8.9 \%)$ & \\
\hline \multicolumn{7}{|l|}{$\mathrm{MCP} 1+2+5+\mathrm{IP} 1$} \\
\hline Negative & $623(84.9 \%)$ & $680(88.7 \%)$ & 0.031 & $656(87.4 \%)$ & $647(86.3 \%)$ & 0.535 \\
\hline Positive & $111(15.1 \%)$ & $87(11.3 \%)$ & & $95(12.6 \%)$ & $103(13.7 \%)$ & \\
\hline \multicolumn{7}{|l|}{$\mathrm{MCP} 1+2+3+5$} \\
\hline Negative & $731(99.6 \%)$ & $766(99.9 \%)$ & 0.364 & $749(99.7 \%)$ & $748(99.7 \%)$ & 1.000 \\
\hline Positive & $3(0.4 \%)$ & $1(0.1 \%)$ & & $2(0.3 \%)$ & $2(0.3 \%)$ & \\
\hline \multicolumn{6}{|l|}{$\mathrm{MCP} 1+2+4+5$} & 0.500 \\
\hline Negative & $734(100 \%)$ & $766(99.9 \%)$ & 1.000 & $751(100 \%)$ & $749(99.9 \%)$ & 0.500 \\
\hline Positive & - & $1(0.1 \%)$ & & - & $1(0.1 \%)$ & \\
\hline \multicolumn{7}{|l|}{$\mathrm{MCP} 1+2+3+5+\mathrm{IP} 1$} \\
\hline Negative & $732(99.7 \%)$ & $766(99.9 \%)$ & 0.484 & $749(99.7 \%)$ & $749(99.9 \%)$ & 1.000 \\
\hline Positive & $2(0.3 \%)$ & $1(0.1 \%)$ & & $2(0.3 \%)$ & $1(0.1 \%)$ & \\
\hline
\end{tabular}




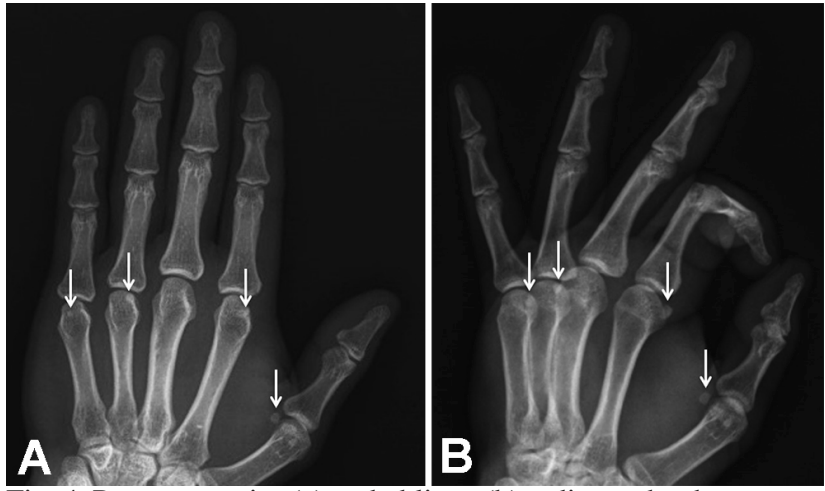

Fig. 4. Posteroanterior (a) and oblique (b) radiographs show a rare distribution of sesamoid bones (arrows) at the first, second, fourth and fifth metacarpophalangeal (MCP) joints. Note that the sesamoid bones on the second and fifth MCP joints are more identifiable in oblique view.
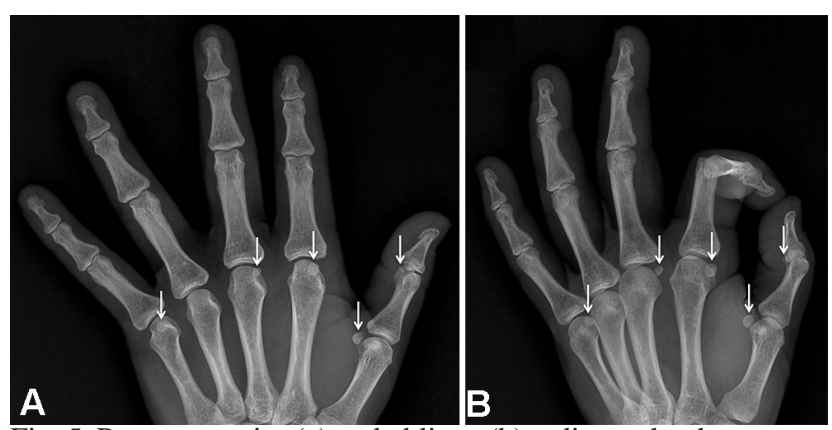

Fig. 5. Posteroanterior (a) and oblique (b) radiographs show a rare distribution of sesamoid bones (arrows) at the first, second, third, fifth metacarpophalangeal and first interphalangeal joints.

Table IV. Comparison of the number of MCP and IP joints with sesamoids in terms of age, sex and hand side. MCP: Metacarpophalangeal, IP: Interphalangeal, r: Spearman's correlation coefficient.

\begin{tabular}{lcc}
\hline Comparisons & $\begin{array}{c}\text { Number of MCP and IP joints } \\
\text { with sesamoids }\end{array}$ & $\mathrm{p}$ \\
\hline Age & 0.102 & $<0.001$ \\
$\mathrm{r}$ & $2.47 \pm 0.04$ & \\
Sex & $2.21 \pm 0.04$ & $<0.001$ \\
Female & & \\
Male & $2.29 \pm 0.04$ & 0.090 \\
Hand side & $2.38 \pm 0.04$ & \\
Right & & \\
Left &
\end{tabular}

\section{DISCUSSION}

There are numerous studies investigating the prevalence of sesamoid bones of the hand among various ethnic groups (Bizarro; Msamati \& Igbigbi; Dharap et al.;
Amar et al.; Kose et al.; Chen et al.). However, most of these studies have not evaluated the coincidence of sesamoid bones, thereby providing prevalence values for each sesamoid bone separately. In this respect, our study, which had the largest series of cases from the Turkish population, is one of the rare studies.

In the present study, all patients $(100 \%)$ had a sesamoid bone at the first MCP joint. Other joints with the highest prevalence of sesamoid bones were the fifth $(58.3$ $\%$ ) and second (40\%) MCP joints, respectively. Considering other relevant studies conducted with the Turkish population, these findings were found to be consistent with the literature (Kose et al., 2012; Koo et al.; Civan et al.). In a study by Kose et al. the prevalence values of sesamoid bones at the first MCP, fifth MCP and second MCP joints were reported to be $100 \%, 53.2 \%$ and $36.6 \%$, respectively. According to another study by Civan et al. the highest prevalence of sesamoid bones was observed at the first MCP joint (100 $\%)$, followed by the fifth $(62.5 \%)$ and second $(36.6 \%) \mathrm{MCP}$ joints. Unlike these studies, our study showed a higher prevalence of sesamoid bones at the IP joint, i.e. $32.5 \%$ ( $21.3 \%$ in the study by Kose et al. and $18.6 \%$ in the study by Civan et al. While there are considerable similarities between studies conducted with the same ethnic groups, it is apparent that prevalence may vary, as observed in sesamoid bones of the IP joint.

Considering the distributions for other ethnic groups, the results were similar for those of Mediterranean, Arabic and European ethnic origin, whereas the second highest prevalence of sesamoid bones followed by the first MCP joint was observed in the second MCP joint instead of the fifth in studies conducted with the Chinese population (Chen et al.; Ting et al.). Reviewing all studies conducted with the Turkish population and other populations from the literature, it was found that the lowest prevalence of sesamoid bones was commonly observed in the third and fourth MCP joints (Msamati \& Igbigbi; Dharap et al.; Amar et al.; Kose et al.; Chen et al.; Ting et al.; Civan et al.).

In the literature, studies on the coincidence of sesamoid bones of the hand and the resulting distribution patterns are very scarce (Joseph, 1951; Ting et al.; Al Khabori et $a l ., 2021)$ and only one study has been conducted with the Turkish population (Kose et al.). The present study showed that sesamoid bones of the hand exhibited 12 different distribution patterns. Among these, the most common pattern was the one that involved the presence of a sesamoid bone at the first MCP joint only. Similarly, the most common distribution pattern was the one with a sesamoid bone at the first MCP joint only, in studies by Kose et al. and Ting et al. Unlike the results of this study, Al 
Khabori et al. and Joseph reported the most common distribution pattern to be the one with sesamoid bones at the first and fifth MCP joints. However, none of the previous studies investigated whether there was a significant difference between sexes and sides in terms of the distribution patterns. In this respect, our study is the first study to investigate if there was such a significant difference and it showed that the pattern with a sesamoid bone at the first MCP joint only was more prevalent among males, whereas the pattern involving coincidence of sesamoid bones at the first, second, fifth MCP and first IP joints was more prevalent among females. There was no significant difference between hand sides in terms of distribution patterns.

Concerning the coincidence of sesamoid bones, it was reported that there was a positive correlation between the second and third MCP joints and the second and fifth MCP joints in the study by $\mathrm{Al}$ Khabori et al. Our study also showed a positive correlation between the same joints as well as between the second MCP and first IP joints, third and fourth MCP joints and between the fifth MCP and first IP joint. This shows that there is a relationship between each sesamoid bone development. This tendency of sesamoid bones to incidentally develop according to certain models at the MCP and IP joints may reflect the influence of genetic factors (Scranton Jr. \& Rutkowski, 1980). On the other hand, it was also theorized that local mechanical stress on the MCP joint could have an impact on sesamoid bone development (Scranton Jr. \& Rutkowski). It is possible to say that the distribution of sesamoid bones of the hand is affected by both genetic and environmental factors, considering the fact that there are various sesamoid bone distribution patterns and there is a positive correlation between certain joints, as seen in this study.

The present study also showed that there was a positive correlation between age and the number of joints with sesamoid bones, which meant that the number of joints with sesamoid bones exhibited an increase in parallel to age. In a study by Sun et al. (2017), investigating the distribution patterns of sesamoids in metatarsophalangeal (MTP) joints, it was reported that the number of sesamoid bones and number of MTP joints with sesamoids had a positive correlation with age, wherein the number of sesamoid bones and the number of joints with sesamoids increased with age (Sun et al.). Ossification of sesamoids typically starts before the age of 20 and continues throughout life. Once they are ossified, sesamoid bones become visible on radiographs. Sun et al. considered the positive correlation they found an indicator that ossification of sesamoids at MTP joints continues after the age of 20 (Sun et al.). Similar findings obtained in the present study also suggest that sesamoid ossification at MCP joints is a lifelong process.
Our study has some limitations. The study is retrospective in design and involves unilateral standard radiographic images. Comments on the prevalence of bilateral sesamoid bones could not be provided since radiographs employed in this study were unilateral. Another limitation of the study is that non ossified sesamoids may have been missed, since only plain radiographs were used for evaluation. Observational errors can be reduced in studies employing $\mathrm{CT}$ or magnetic resonance imaging (MRI). The strengths of our study consist of the large sample size and the fact that all radiographs were obtained with a digital $\mathrm{x}$-ray machine. Therefore, sesamoid bones could be identified more accurately by changing the parameters such as contrast and brightness, as desired. Moreover, observational errors could be reduced since evaluations were independently performed by a radiologist and an orthopedist.

In conclusion, we reported the prevalence, distribution patterns and coincidence of MCP sesamoid bones by identifying 12 different patterns of sesamoid bone distribution with a large sample size consisting of the Turkish population. Sesamoid bones of the hand may lead to confusion, since they are frequently overlooked in patients presenting with pain and they can be misdiagnosed as fractures in trauma patients. Therefore, this study is important in that it provided anatomical data that can be guiding for clinicians in terms of diagnosis and management. The results of this study have shown that the most common distribution pattern of sesamoid bones of the hand is the one with sesamoid at the first MCP joint only and there is a positive correlation between certain joints in terms of sesamoid bone presence. Moreover, the number of joints with sesamoids was found to increase with age.

YILDIZ, G.; GURSOY, M.; BULUT, T.; METE, B. D. \& COBAN, I. Patrones de prevalencia, coincidencia y distribución de los huesos sesamoideos de la mano. Int. J. Morphol., 39 (5):1399-1405, 2021.

RESUMEN: El objetivo de este estudio fue identificar la prevalencia y los patrones de distribución de los huesos sesamoideos en las articulaciones metacarpofalángicas (MCF) e interfalángicas (IF) y determinar si existe una asociación entre los patrones de distribución y la edad, el sexo y el lado de la mano; fueron evaluadas retrospectivamente radiografías de la mano obtenidas en 2019 2020. Todas las radiografías se evaluaron en términos de prevalencia, coincidencia y patrones de distribución de los huesos sesamoideos. También se evaluó la presencia de una asociación entre los patrones de distribución y la edad, el sexo y el lado. Se incluyeron en el estudio un total de 1501 radiografías de mano. Se observaron 12 patrones diferentes de distribución de los huesos sesamoideos. El patrón de distribución más común fue la presencia de hueso sesamoideo solo en la primera articulación $\operatorname{MCF}(25,8$ $\%)$. Hubo una correlación positiva entre la segunda y la tercera 
MCF, la segunda y la quinta MCP, la segunda y la primera IF, la tercera y cuarta MCF y la quinta MCF y las primeras articulaciones IF. El patrón con un hueso sesamoideo en la primera articulación $\mathrm{MCF}$ fue más prevalente entre los hombres, mientras que el patrón de coincidencia de los huesos sesamoideos en la primera, segunda, quinta articulación MCF y la primera articulación IF fue más prevalente entre las mujeres ( $\mathrm{p}<0.001, \mathrm{p}=0,031)$. Se observó una correlación positiva entre la edad y el número de articulaciones MCF con huesos sesamoideos ( $\mathrm{p}<0,001)$. El número de articulaciones MCF con huesos sesamoideos era mayor en las mujeres ( $p<0,001)$. Este estudio es importante debido a que proporcionó datos anatómicos que pueden ser una guía para los médicos en el diagnóstico y tratamiento de los trastornos de la mano.

PAlabras ClaVE: Coincidencia; Patrón de distribución; Mano; Articulación metacarpofalángica; Huesos sesamoideos.

\section{REFERENCES}

Al Khabori, H.; Al Asmi, M.; Sirasanagandla, S. R.; Al Rashdi, F.; Al Dhuhli, H.; Jaju, S. \& Al Mushaiqri, M. Prevalence and distribution of sesamoid bones of the hand in Omani subjects: a radiological study. Anat. Sci. Int., 96(1):79-86, 2021.

Amar, E.; Rozenblat, Y. \& Chechik, O. Sesamoid and accessory bones of the hand-an epidemiologic survey in a Mediterranean population. Clin. Anat., 24(2):183-7, 2011.

Bizarro, A. H. On sesamoid and supernumerary bones of the limbs. J. Anat., 55(Pt. 4):256-68, 1921.

Chen, W.; Cheng, J.; Sun, R.; Zhang, Z.; Zhu, Y.; Ipaktchi, K. \& Zhang, Y. Prevalence and variation of sesamoid bones in the hand: a multi-center radiographic study. Int. J. Clin. Exp. Med., 8(7):11721-6, 2015.

Civan, O.; S, ekerci, R.; Ercıktı, N.; Özer, S .; Güvenç, I .; Çevik, N. K. \& Özcanl1, H. Sesamoid bones of the hand: A multicenter study. Jt. Dis. Relat. Surg., 31(1):68-72, 2020.

Dharap, A. S.; Al-Hashimi, H.; Kassab, S. \& Abu-Hijleh, M. F. Incidence and ossifcation of sesamoid bones in the hands and feet: a radiographic study in an Arab population. Clin. Anat., 20(4):416-23, 2007.

Joseph, J. The sesamoid bones of the hand and the time of fusion of the epiphyses of the thumb. J. Anat., 85(3):230-41, 1951.

Koo, B. S.; Song, Y.; Sung, Y. K.; Sung, I. H. \& Jun, J. B. Prevalence and distribution of sesamoid bones in the hand determined using digital tomosynthesis. Clin. Anat., 30(8):608-13, 2017.

Kose, O.; Guler, F.; Turan, A.; Canbora, K. \& Akalin, S. Prevalence and distribution of sesamoid bones of the hand. A radiographic study in Turkish. Int. J. Morphol., 30(3):1094-9, 2012.

Msamati, B. C. \& Igbigbi, P. S. Radiographic appearance of sesamoid bones in the hands and feet of Malawian subjects. Clin. Anat., 14(4):248-53, 2001.

Scranton Jr., P. E. \& Rutkowski, R. Anatomic variations in the first ray: Part II. Disorders of the sesamoids. Clin. Orthop. Relat. Res., (151):25664,1980

Sun, T.; Zhao, H.; Wang, L.; Wu, W. \& Hu, W. Distribution patterns and coincidence of sesamoid bones at metatarsophalangeal joints. Surg. Radiol. Anat., 39(4):427-32, 2017.

Ting, L. G. Y.; San, C. E. C.; Ben, N.;Gerry, H. C. H. \& Wai, C. C. Distribution of sesamoid bones in the hand: a study in the Chinese population. J. Orthop. Trauma Rehabil., 23(1):45-8, 2017.

Yammine, K. The prevalence of the sesamoid bones of the hand: a systematic review and meta-analysis. Clin. Anat., 27(8):1291-303, 2014.
Corresponding Author:

Tugrul Bulut, AssocProf, MD

Izmir Katip Celebi University

Faculty of Medicine

Ataturk Training and Research Hospital

Department of Orthopaedics and Traumatology

35360, Basın Sitesi

Karabaglar Izmir

TURKEY

E-mail: drtugrulbulut@yahoo.com

Received: 09-05-2021

Accepted: 13-07-2021 